\title{
20 Years of AMIRA P266 "Improving Thickener Technology" - How has it Changed the Understanding of Thickener Performance?
}

P.D. Fawell Parker Centre (CSIRO Minerals), Australia

J.B. Farrow Parker Centre (CSIRO Minerals), Australia

A.R. Heath Parker Centre (CSIRO Minerals), Australia

T.V. Nguyen Parker Centre (CSIRO Minerals), Australia

A.T. Owen Parker Centre (CSIRO Minerals), Australia

D. Paterson CSIRO Materials Science and Engineering, Australia

M. Rudman CSIRO Mathematical and Information Sciences, Australia

P.J. Scales Department of Chemical and Biomolecular Engineering, The University of Melbourne, Australia

K. Simic Parker Centre (CSIRO Minerals), Australia

D.W. Stephens Parker Centre (CSIRO Minerals), Australia

J.D. Swift Parker Centre (CSIRO Minerals), Australia

S.P. Usher Department of Chemical and Biomolecular Engineering, The University of Melbourne, Australia

\begin{abstract}
As the expectations for more consistent and higher density thickened and paste tailings increase, so do the demands on thickener performance. Over the last 20 years, the AMIRA P266 "Improving Thickener Technology" series of projects, have significantly advanced the understanding of thickening by combining fundamental investigations of flocculation, advanced mathematical and computational modelling and pilotscale measurement/validation. This has produced unique tools for thickener design and optimisation. The major outcomes from $P 266$ over this 20 year period are reviewed.
\end{abstract}

\section{Introduction}

Solid-liquid separation by gravitational settling has long been used in many applications. Gravity thickeners (Figure 1) enable the treatment of vast volumes of dilute slurry that pass through a central feedwell, with the intention of dissipating much of the incoming stream's kinetic energy and gently discharging this stream into the main tank volume. The solids settle to form a bed, with solids concentration increasing towards the underflow at the base (Svarovsky, 2000). Clarified liquor is collected at the peripheral overflow, while a centrally driven rake promotes consolidation and assists sediment transport to the underflow discharge.

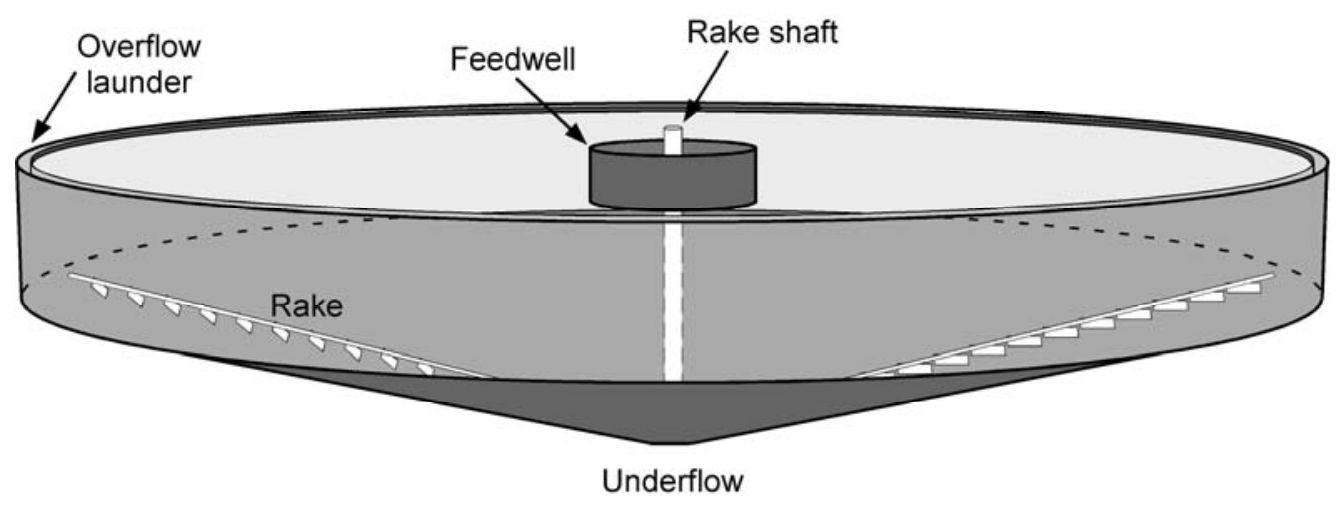

Figure 1 Conventional gravity thickener 
The introduction of synthetic polymer flocculants able to form large, fast settling aggregates provided the potential for greater throughputs and smaller thickeners. The flocculation process requires mixing of the flocculant solutions with the incoming feed, with feedpipes and feedwells the obvious addition points. Such systems have rarely been optimised for flocculation, although some modern designs acknowledge the need for solids and flocculant dilution to enhance aggregation. Sub-optimal flocculation may not be an issue in many large, over-sized conventional thickeners with low rise velocities. However, the trend towards highrate and paste thickening, as well as environmental and capital restrictions, places higher demands on flocculation and thickening performance in terms of throughput, clarity and underflow properties.

\section{AMIRA P266}

The AMIRA P266 "Improving Thickener Technology" project was initiated in 1988 with the support of 14 companies from the minerals industry, who recognised that thickener designs of the time had developed primarily through experience. In particular, it was felt that previous fundamental studies in the area did not offer sufficient insights for practical operational issues. This level of support (which has grown in subsequent stages) led to the formation of a large multi-disciplinary team and an unprecedented extensive work program that combined fundamental chemical and physical characterisation, advanced mathematical modelling and pilot and full-scale measurements. Some of the main developments in each of the six stages of AMIRA P266 to date are summarised below:

- P266 (1988-91) identified that agitation conditions used to mix flocculant with feed were the dominant influence on flocculation and hence thickener performance. A prototype "Shear Vessel" became an important laboratory flocculation tool. A floc density analyser (FDA) provided microscopic characterisation of aggregate size and settling, particularly in overflows. Full-scale profiling with a natural $\gamma$-ray gauge was used to develop a dynamic 1-D model of bed formation.

- In P266A (1993-95), performance measures such as flocculant consumption, underflow density and throughput were related to the mixing conditions during flocculation through laboratory and site studies. There was considerable scope at most sites to improve thickener operation by optimising flocculation. Hydrodynamics studies began with the development of a two-phase Computational Fluid Dynamics (CFD) feedwell/thickener model, experimentally validated on full-scale units.

- The 12 month P266B project (1996-97) at Iluka's operations (Capel, Western Australia) used twin tailings thickeners to test feedwell concepts from P266A, demonstrating the impact of flocculation conditions (e.g. mixing, residence time and solids concentration) on performance. Focused beam reflectance measurement (FBRM, Mettler Toledo) was used to monitor aggregate growth in the first linear pipe reactor study of flocculation kinetics. The capacity to predict suitable flocculant sparge locations from feedwell CFD was gained by introducing a mathematical description of flocculant adsorption. This was successfully used to optimise sparge locations for the Iluka thickeners.

- Validation of CFD in P266C (1998-2000) gave confidence in its use to predict feedwell performance for a range of designs. Flocculation kinetics measurements with the pipe reactor (in the laboratory and on-site) determined the effects of solids concentration, turbulence levels, flocculant type and dosage. Population balance (PB) modelling was initiated to mathematically describe the kinetics of aggregate growth and rupture. The first fundamental understanding of rake action was developed, through the coupling of CFD, pilot-scale thickener studies and small-scale physical measurements.

- P266D (2001-04) saw extensive use of the pipe reactor with different mineral feeds. It confirmed the applicability of the PB to describe flocculation over a range of conditions. The full implementation of the PB into CFD code produced a powerful new tool for improving full-scale thickener performance. For the first time CFD models were formulated to describe (in 3D) settling, sediment formation and sediment transport by rakes within full-scale thickeners of any design. However, these models were not fully linked and PB-CFD was computationally time-consuming. Quantifying the impact of shear on bed dewatering remained a major impediment to full thickener modelling.

- A small-scale pipe reactor developed in P266E (2005-08) provided rapid approximation of PB parameters required for PB-CFD feedwell optimisation. The PB-CFD was transferred into a more advanced and highly customised version of the CFD software - this allowed the first effective (if 
limited) linkage of feedwell, sedimentation and raking models. Modelling and pilot-scale tracer studies investigated a range of rake designs and the first estimates made of shear rates imparted by raking. New procedures for examining the impact of shear on settling/consolidating aggregates sought to quantify aggregate breakage vs. densification. A number of feedwell design elements were modelled, and a re-investigation of all previous modelling allowed design rules and guidelines to be drawn. A novel feedwell design was developed, based on an understanding of requirements for optimum flocculant/slurry mixing and energy dissipation. CFD predicts this design will maintain performance over a broader range of process conditions than most feedwells currently used.

The following sections provide a general introduction to some of the main outcomes and the implications for thickener design, operation and performance. Much of the focus is on the feedwell, which is understandable, given that feedwell performance has such a major impact on all aspects of thickener performance. However, specific aspects of sedimentation and raking are discussed separately.

\section{$3 \quad$ Feedwell}

\subsection{Understanding the flocculation process}

A significant benefit delivered to sponsors of the P266 projects has been an enhanced understanding of the operational factors influencing the flocculation of minerals systems, redressing deficiencies in the published literature that are still perpetuated to this day. Many academic studies are on low density, sub-micron sized standard substrates at high effective surface coverage, for which aggregation behaviour is very different from mineral systems that are of higher density and typically much coarser (see Owen et al., 2008, for a detailed discussion). Studies that consider real mineral systems often suffer from poorly defined mixing procedures (e.g. cylinder/jar or stirred beaker tests) in which critical aspects of the flocculation process may be masked.

The Shear Vessel provides continuous flocculation in a Couette device, with good control of the intensity and duration of applied mixing and much greater reproducibility than cylinder tests (Farrow and Swift, 1996a). This proved a highly successful tool in discerning between flocculants with different optimum shear or residence time requirements, as well as identifying deficiencies in flocculant make-up and delivery procedures (Farrow and Swift, 1996b; Owen et al., 2007). Application of the Shear Vessel demonstrated the critical role of applied mixing to the extent and efficiency of flocculation, as well as the kinetics of aggregate growth and breakage. However, a more advanced technique was required to quantify such effects in a way that could be utilised with feedwell modelling.

The capacity to achieve real-time characterisation of aggregate size with FBRM probes, in turbulent pipe flow led to the development of a linear pipe reactor to quantify flocculation kinetics (Heath, 2002; Swift et al., 2004; Heath et al., 2006a; Owen et al., 2008). A versatile system was constructed, based on pipe lengths up to $40 \mathrm{~m}$ in length (usually $22 \mathrm{~mm}$ ID), with tight control of reaction time, flow rate, solids concentration and flocculant dosage, allowing reaction time profiles for aggregate size and settling rate to be constructed for known mean shear rates. Typical data for kaolin flocculation at different mean shear rates is shown in Figure 2a. Such profiles, acquired over a broad range of conditions for a standard substrate, were then used in the development of the flocculation PB model (Heath et al., 2006b), a series of mathematical equations describing the aggregate size distribution through time. While other aggregation PB models exist, this was the first to capture the irreversible breakage of aggregates at longer reaction times that is a characteristic of polymer-bridging flocculation in mineral systems (evident in Figure 2a for the higher mean shear rates). In P266D and P266E, the PB model was successfully applied to pipe reactor kinetics results obtained with thickener feeds at different sponsor sites, generating parameter sets that characterize the system and allow direct customisation of feedwell PB-CFD (Section 3.2) for that system.

Separate from the PB model, the pipe reactor has provided many insights on the flocculation process. For example, the decline in the settling rates at longer reaction times is greater than expected from the corresponding size measurements alone (Owen et al., 2008). Experiments in which flocculation was initiated in a region of high shear (narrow pipe) before then passing into lower shear (wide pipe) indicated that adsorbed flocculant remained active at short reaction times, allowing additional aggregate growth under subsequent reduced shear (Figure $2 b$ ). This surface flocculant is deactivated at longer reaction times under higher shear (re-conformation or shear degradation), preventing or greatly reducing additional growth. 

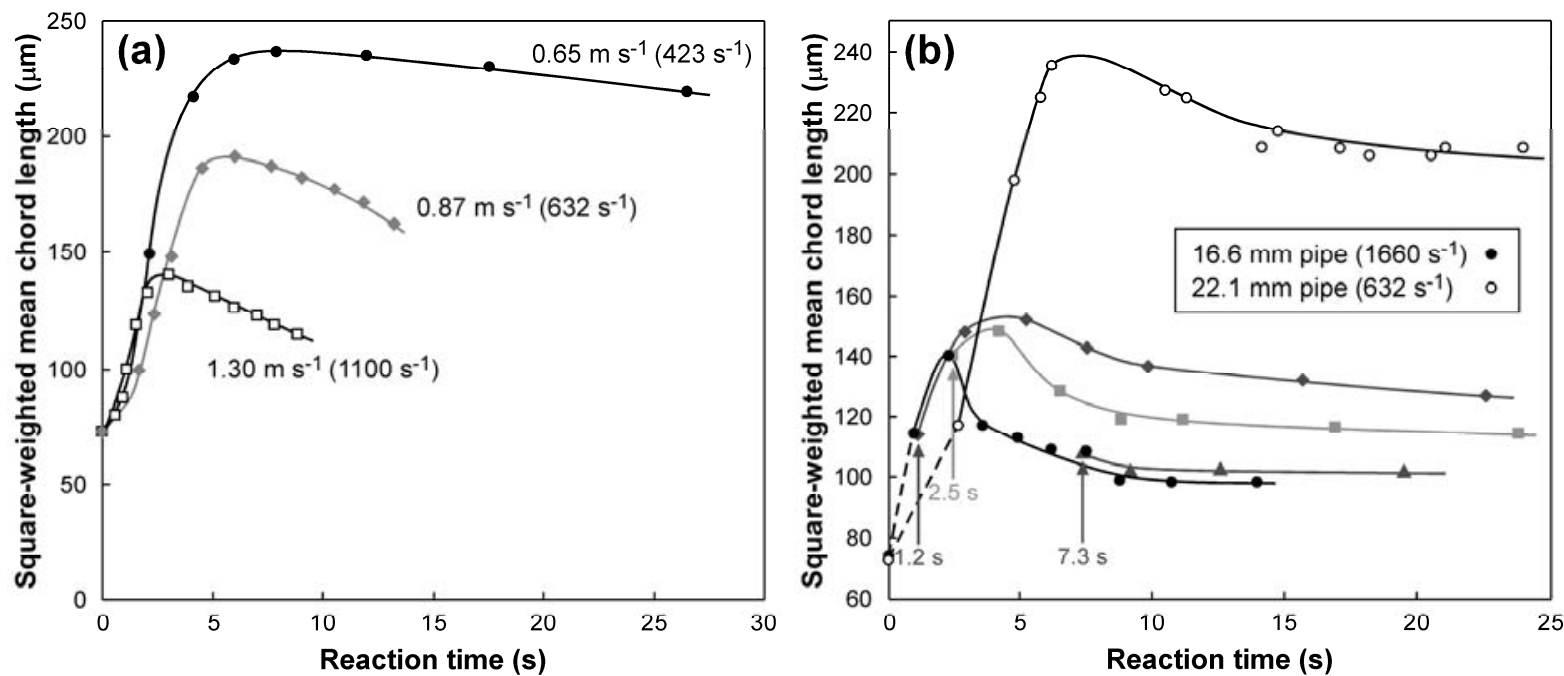

Figure 2 Aggregate size as a function of reaction time for pipe reactor flocculation of standard kaolin $\left(21 \mathrm{~g} \mathrm{~L}^{-1}\right)$ with a $35 \%$ anionic flocculant (Owen et al., 2008). (a) Effect of flow rate at a dosage of $64 \mathrm{~g} \mathrm{t}^{-1}$; (b) Effect of a reduction in agitation intensity at a dosage $67 \mathrm{~g} \mathrm{t}^{-1}$ and slurry flow rate $20 \mathrm{~L} \mathrm{~min}^{-1}$ - shaded points represent a change to a $22.1 \mathrm{~mm}$ diameter pipe after the marked intervals

The disadvantage of the pipe reactor as applied above is the large feed volumes required ( $1-5 \mathrm{~kL}$ per day), which means most measurements need to be done with direct tapping of a thickener feed. A small-scale pipe reactor was developed. This reduced the required volumes to 200-400 L, making customisation of the model to a specific thickener feed more viable in terms of cost and time.

\subsection{Feedwell modelling}

In recent years a number of publications have appeared that use CFD to describe hydrodynamics within clarifiers, thickeners and other industrial settling devices (Wood et al., 1995; Laine et al., 1999; Brouckaert and Buckley, 1999; Baek et al., 2005; Dixon et al., 2003; Flamant et al., 2004; Templeton et al., 2006; Kleine and Reddy, 2006; Weiss et al., 2007; Goula et al., 2008). However, the majority are related to non-minerals applications (e.g. sewage, wastewater) and do not directly consider feedwells, being more concerned with flows in the settling zone. Feedwell CFD has undoubtedly been done by thickener manufacturers, but rarely published in any detail. Peloquin et al. (2005) applied conventional CFD to a bauxite residue feedwell and thickener (final washing stage) to show the effect of mean particle size, flow rate and feedwell diameter on flow patterns.

The equivalent work associated with P266 can be differentiated through advances in turbulence modelling and validation (White et al., 2003), but most of all through the inclusion of 3D predictions of flocculant adsorption (Kahane et al., 2002) and, most recently, aggregate size from PB-CFD (Nguyen et al., 2006). To the best of our knowledge, the PB-CFD capability developed in P266 is the most sophisticated and powerful available for feedwell studies. It provides information on feedwell flocculation performance that cannot be derived from conventional CFD predictions of fluid flows and solids concentrations.

There are many different feedwell designs in use around the world, but the most common general designs are shown in Figure 3. 'Open' feedwells are essentially open cylinders around the central rake shaft, while in the 'closed' design, the cylinder tapers to a narrower outlet, generally with a deflector cone around the shaft. Open feedwells are best fed tangentially, either with single or split feed entries - closed feedwells typically have a single tangential feed entry. The images in Figure 3 are not to scale, nor to any preferred height: diameter ratio or feed inlet diameter, and design elements such as shelves, dilution slots and baffles are not shown. Feed entry is known to be at right angles to the feedwell wall in some older units, but this generally leads to the feedwell volume being very poorly utilised. These designs are not considered here. 


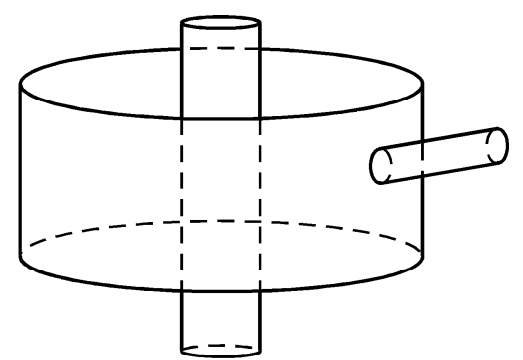

Open - tangential feed

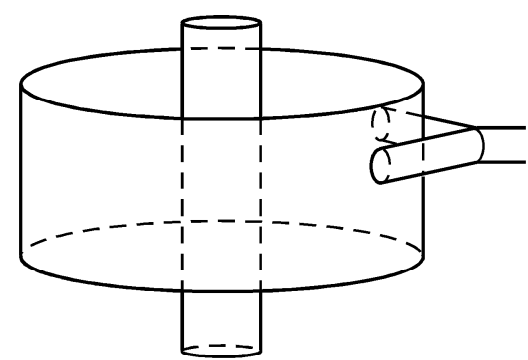

Open - split feed

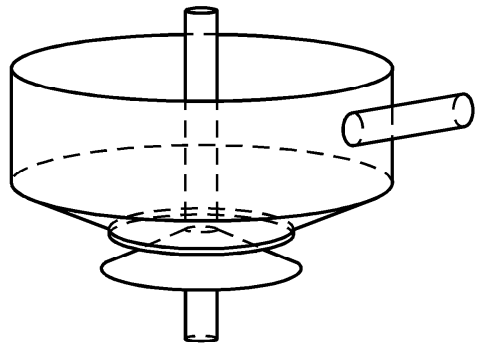

Closed - tangential feed

Figure 3 General feedwell designs (not to scale and not showing all potential design elements)

No generic feedwell design has overall superior performance. Many factors (e.g. feed flow rate, particle size, solids concentration, throughput) will influence the choice of one design over another, as well as the desired performance criteria (stability, response to variations in the process condition, underflow density, clarity, etc). Importantly, the performance of both open and closed feedwells is highly dependent upon their design. Using the CFD modelling techniques developed in the course of the P266 projects, it has been clearly demonstrated that there is considerable scope to enhance the hydrodynamic and flocculation performance of both open and closed feedwell designs through relatively minor engineering modifications, such as feedpipe diameter or angle, skirt length and shelves location or width (e.g. Kahane et al., 2002).

However, feedwell modelling does predict that the simple open design without modification offers inefficient performance on a number of levels. Figure $4 \mathrm{a}$ shows that for a typical volumetric throughput, the feed stream will sink rapidly; aggregate growth is slight and some particles are predicted to leave the feedwell without contacting flocculant, indicating poor mixing. Throughput is typically maintained by increasing flocculant dosages, but the resultant localised overdosing can have a detrimental impact on bed and subsequent underflow properties.
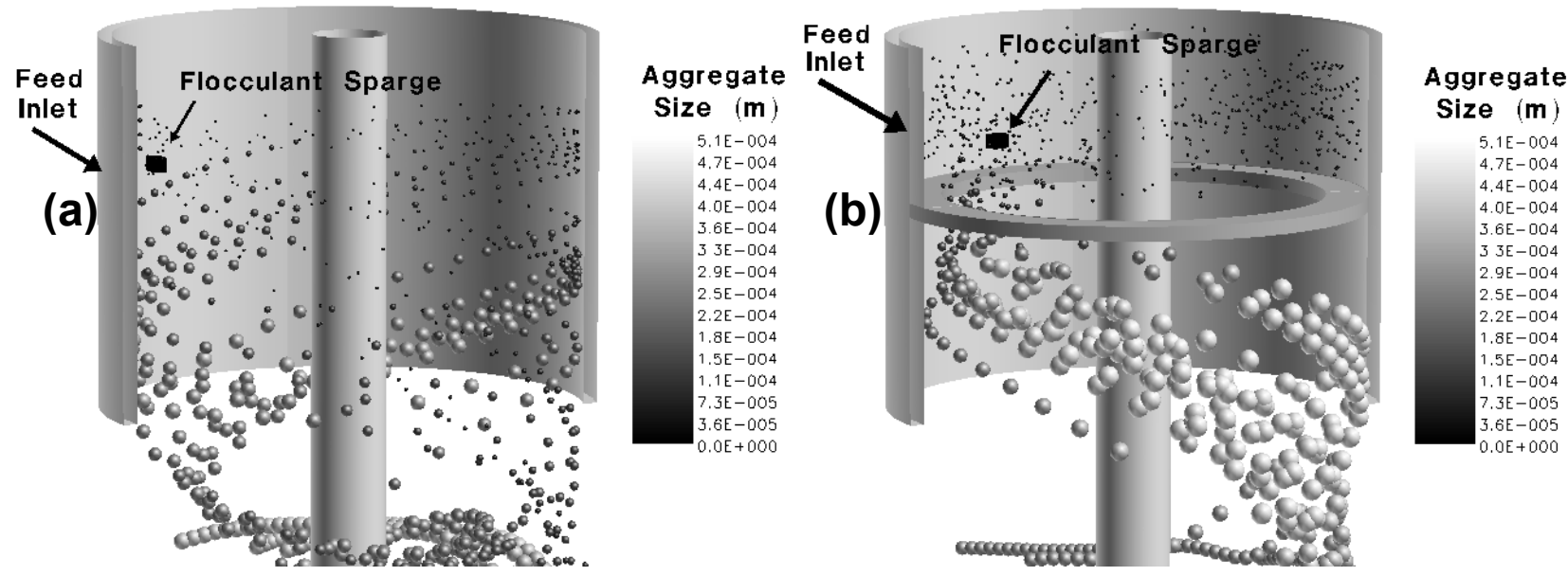

Figure 4 PB-CFD predictions of aggregate size and flow for (a) open and (b) open with shelf feedwells at a volumetric flow rate of $1000 \mathrm{~m}^{3} \mathrm{~h}^{-1}$ for a $50 \mathrm{~g} \mathrm{~L}^{-1}$ calcite feed (feedwell $4 \mathrm{~m}$ diameter, $3 \mathrm{~m}$ high, $0.50 \mathrm{~m}$ diameter single tangential feed inlet, feed $d_{4 / 3} 24 \mu \mathrm{m}$, flocculant dosage $20 \mathrm{~g} \mathrm{t}^{-1}$ )

In contrast, the simple addition of a shelf below the feed inlet prevents the feed stream from rapidly sinking (Figure $4 \mathrm{~b}$ ), thereby maintaining the horizontal component of the swirling flow for longer, increasing the residence time within the upper zone of the feedwell and ensuring solids are more evenly distributed on discharge. Mixing is much more effective, with aggregate growth favoured as the solids fall off the shelf and aggregate size maximised near the discharge plane of the feedwell. An open feedwell without a shelf is highly unlikely to be recommended for any new installation. As such, any comparison between open and closed designs should be based on the use of a shelf in the former. 
Other general conclusions regarding feedwell design and operation include:

- The flocculant addition (sparge) point is a critical part of feedwell design and operation, determining how the hydrodynamics influences flocculant distribution and flocculation. While upstream addition favours flocculant distribution and adsorption, reducing the risk of unadsorbed flocculant reaching the overflow (harmful to some downstream processing), this will usually expose the aggregates to excessive shear. CFD is an ideal tool for investigating the balance between these processes.

- There is an optimal range for the feed inlet velocity (derived from CFD) which is dependent on feed properties and feedwell design. Too low a velocity leads to poor mixing and an insufficient horizontal component to the swirling flow, such that the upper region of the feedwell is not well utilised. Too high a velocity can be detrimental to flocculation, and may necessitate moving sparge locations. Many feedwells are operated outside their designed range, in which case changing the diameter of feed inlet may be much more practical than changing that of the feedwell.

- The split feed entry arrangement is often utilised in high throughput applications. In low aspect ratio feedwells (i.e. small diameter) with shelves, the opposing feeds should collide at the opposite wall and combine before dropping vertically. Achieving an even split of the streams is difficult, and this can lead to some instability in performance. In the absence of shelves, the streams may short-circuit from the feedwell and preferentially discharge to one side. Such problems are exacerbated in higher aspect ratio feedwells (i.e. large but shallow, used to minimise side wall height above the rakes), for which even the presence of shelves cannot fully eliminate asymmetric discharge. A number of design options for maintaining turbulence and residence times in shallow feedwells have been modelled, including some alternative concepts from the manufacturers (e.g. Triglavcanin, 2008).

- It has long been known that feedwell discharge can affect high beds, with the potential for scouring and solids entrainment the overflow. However, high beds can also act as a partial barrier to discharge, the feedwell then drawing in solids from the bed. This will impact on flocculation, in most cases reducing aggregate size. Modelling should therefore always consider the bed position.

In P266E a new feedwell design concept was developed, based on the understanding gained from the ongoing CFD studies. This design is thought to offer better performance across a wider range of operational conditions than conventional feedwells, and is currently undergoing full-scale trials.

\section{Sedimentation}

There are numerous published models that describe sedimentation within thickeners (e.g. Bürger et al., 1999; Martin, 2004; Usher and Scales, 2005). Their merits vary, but all suffer in that:

(i) None are fully predictive, i.e. at best they provide predictions across a range of solids concentrations for one flocculation state, but cannot be extended to another flocculation state without new inputs.

(ii) None can account for the effect of post-flocculation shear (e.g. raking) on aggregate structures; this leads to substantial under-prediction of underflow densities.

The changes in aggregate structure on passage through a thickener were recognised in the original P266 project, with the FDA used to confirm that underflow samples (taken prior to the pump) were smaller and denser than those from the feedwell (Farrow and Swift, 1991). Similar studies with a continuous pilot column were combined with full-scale bed profiling with a $\gamma$-ray gauge to quantify the extent of dewatering from raking (Farrow et al., 2000). In P266D, hindered setting and compressibility were characterised for flocculated calcite suspensions that had been subjected to a range of post-formation shear rates (Gladman et al., 2005; Scales et al., 2006). A critical shear rate $\left(\sim 6 \mathrm{~s}^{-1}\right)$ for enhanced dewatering was observed, above which aggregate breakage was believed to dominate over densification.

Theoretical analysis in P266E has demonstrated the potential impact on dewatering of even small changes in aggregate diameter $\left(d_{\text {agg }}\right)$ from densification. Figure 5a predicts the increase in settling velocity as a function of solids volume fraction, while Figure $5 \mathrm{~b}$ shows the corresponding permeability enhancement factor $(P E$, the ratio of the settling velocities with and without densification). $P E$ values in excess of 10 are possible for a reduction in $d_{\text {agg }}$ of only $20 \%$. 

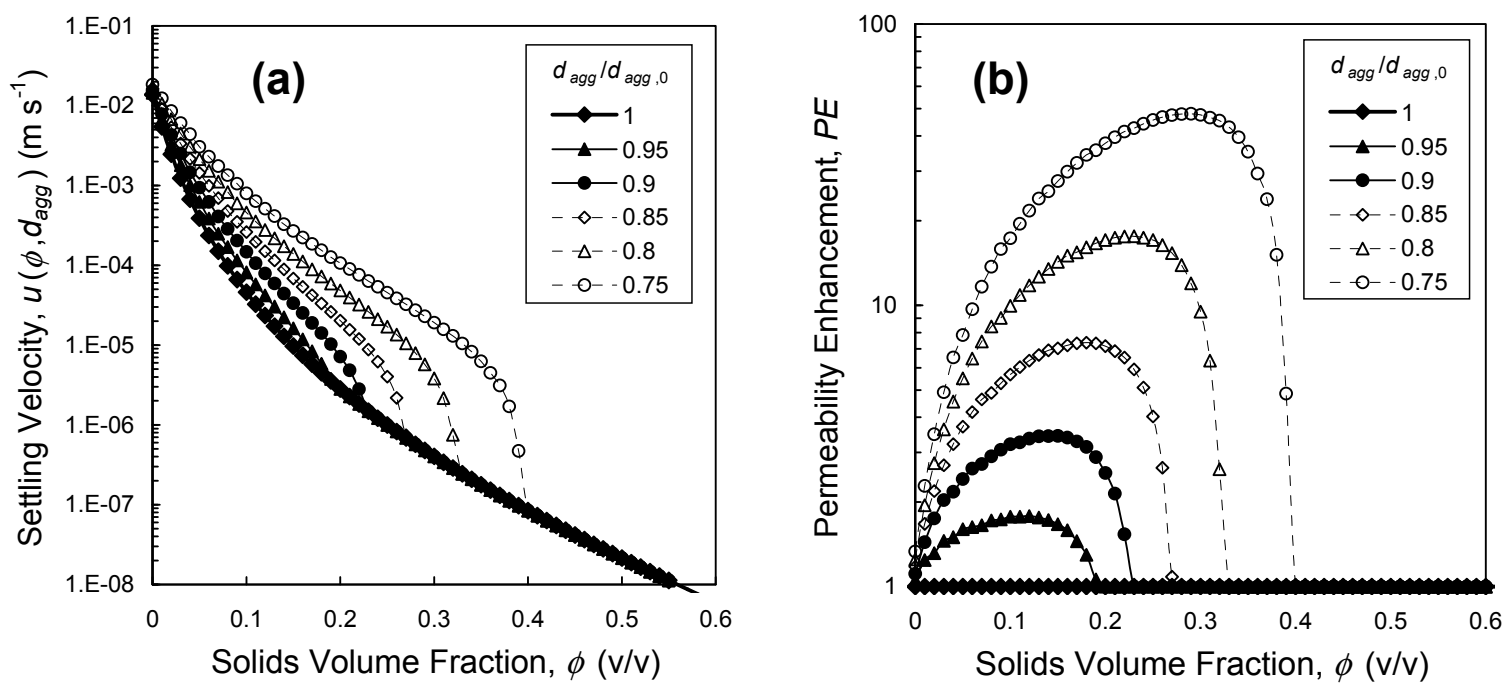

Figure 5 Variation of (a) overall settling velocity and (b) permeability enhancement factor (PE) versus solids volume fraction for a range of aggregate densification extents ranging from the original aggregate diameter, $d_{\mathrm{agg}, 0}$, to $d_{\mathrm{agg}} / d_{\mathrm{agg}, 0}=0.75$

Challenges still exist to mathematically describe the physical processes that may take place to change aggregate structures after feedwell flocculation (both during passage to the bed and from raking) and to incorporate this in an overall sedimentation model. The sedimentation of pipe reactor flocculated solids is being characterised in-line, providing the experimental basis for model development.

In parallel, the numerical framework has been put in place for full thickener CFD, linking sub-models for feedwell flocculation, sedimentation and raking. The entire thickener flow domain can now be modelled by CFD, although the model is incomplete with respect to sedimentation and how the zones interact. Figure 6 shows the predicted solids distribution within a thickener that includes hindered settling and a Bingham rheology formulation for the yield stress of the networked bed. Some issues with this numerical framework do exist, but the main barrier to progress remains the understanding of physical processes.

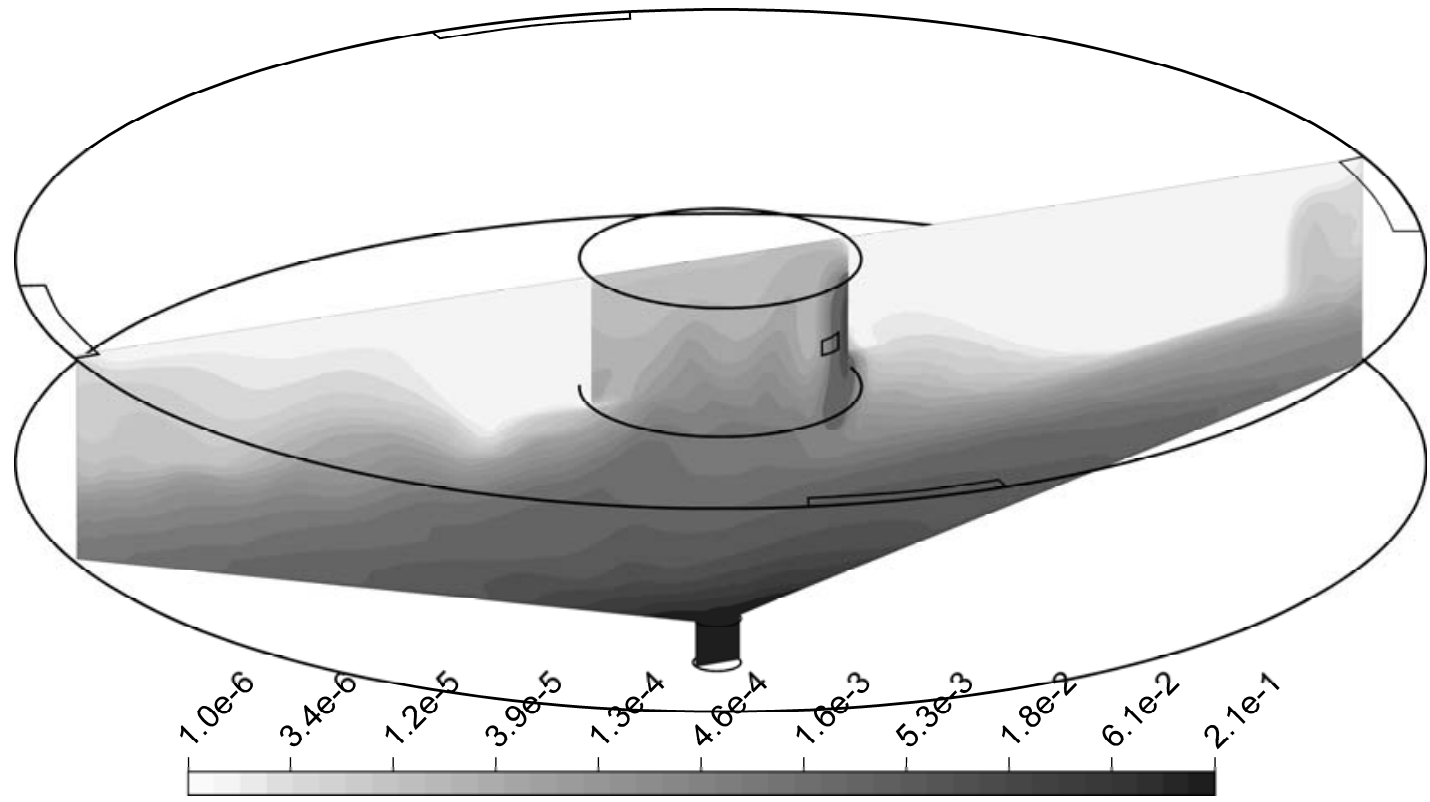

Figure 6 CFD predicted solid distribution within a thickener, with Bingham rheology used in modelling of the sediment bed (logarithmic contour spacing for solids volume fraction) 


\section{$5 \quad$ Raking}

As stated above, rakes assist in dewatering sediment within the thickener bed, but they also move these sediments to the underflow. There have been few studies of rake design and transport, and until P266, no published measurements or modelling of flow around rake arms and blades. A small-scale (1.07 m diameter) raked model thickener was built in P266C, with optically clear gel simulating the bed (Šutalo et al., 2003). Flow visualisation was carried out by monitoring coloured dye blobs as they were moved by different rake designs, while Particle Image Velocimetry by laser illumination of silver-coated tracer particles provided velocity fields. Overall transport from the tank periphery to the underflow clearly occurred at the level of the rake blades, visible as a spiral pattern taking several revolutions to traverse the distance. Good agreement was achieved between velocity measurements and CFD predictions for individual rake components, but no CFD simulations of global transport were presented.

Greater confidence in the CFD rake model and its extension to global transport for homogenous beds were obtained from validation in a $2 \mathrm{~m}$ diameter pilot-scale thickener, with flocculated, fine particle thickener underflows used to approximate a thickener bed. Torque measurements, together with residence time distributions derived from addition of a tracer (dyed kaolin, added to the bed at locations shown in Figure 7, with an optical detector at the underflow), were compared with CFD predictions (Rudman et al., 2008).
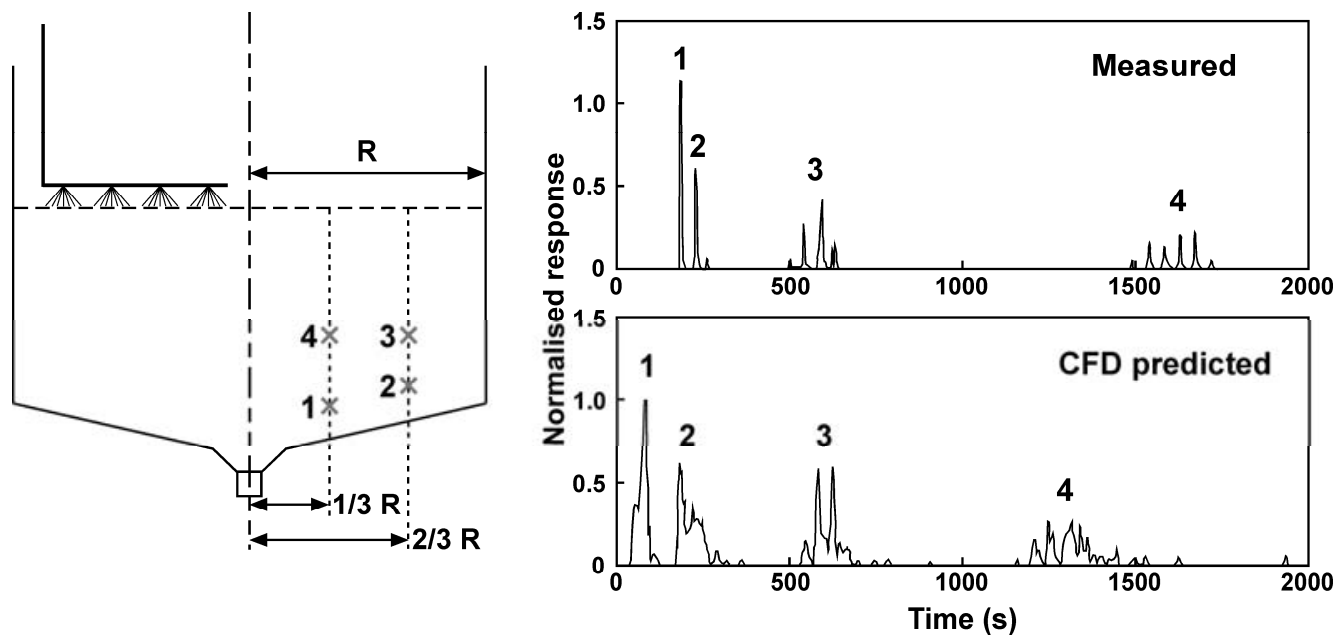

Figure 7 Measured and CFD predicted profiles for solid tracer (dyed kaolin) added at four different locations to a homogenous clay bed raked with constant height blades at $0.67 \mathrm{rpm}$ (adapted from Rudman et al., 2008)

For constant height rake blades, Figure 7 shows that the tracer from the different locations appeared in the order 1-2-3-4, which agrees well with CFD predictions. This is clear evidence that the outer rake blades are over-delivering, such that material is being pushed upwards and back out to the periphery.

CFD can be used to optimise the height, size, spacing and number of rake blades to achieve desired delivery and minimise rake torque. While minimising recirculation arising from rake over-delivery may be important in a scaling environment, the question remains as to whether such recirculation is actually beneficial for dewatering. Knowledge of the shear rates in a thickener bed is essential for the eventual prediction of how shear influences dewatering. Compression alone does cause dewatering, but adding shear from raking greatly enhances dewatering characteristics, underflow density and water recovery (Farrow et al., 2000).

In P266E, shear strain rates in the bed of a generic full-scale thickener were predicted from a CFD study considering sediment yield stress, rake rotation rate and blade height. Although much of the bed experienced very low shear rates, a fraction does encounter higher shear rate regions during passage to the underflow. The maximum shear rates predicted were still very much lower than those within feedwells, but were within the range of shear rates found from experimental dewatering studies to favour aggregate densification over breakage. This represents the first predictions of shear rates from raking; such information for different rake designs and configurations will ultimately lead to designs and strategies to optimise underflow and paste properties, without major rake torque penalties. 


\section{The future}

The insights gained to date from the P266 projects have provided a firm scientific basis for feedwell and thickener design, a necessity as operational requirements become more stringent. Project outcomes have been applied to enhance the performance of over 200 thickeners world-wide for companies sponsoring P266.

AMIRA P266F commenced in late 2008, with the over-riding objective of achieving full thickener modelling capabilities, i.e. the practical linking of feedwell, sedimentation and raking models, such that underflow properties can be predicted simply from knowledge of unit dimensions, volumetric flows, feed properties and the initial flocculation regime. All the required sub-models are well advanced with the exception of that describing sedimentation and dewatering. The work program of $\mathrm{P} 266 \mathrm{~F}$ is therefore focused on providing an experimental basis for developing a fully-predictive sedimentation model. P266F will also expand upon processes from $\mathrm{P} 266 \mathrm{E}$ related to technology transfer to sponsoring companies.

\section{Acknowledgements}

The authors thank the following sponsors of the AMIRA P266 'Improving Thickener Technology' series of projects for their support: Albian Sands Energy, Alcan, Alcoa World Alumina, Anglo Gold, Anglo Platinum, Bateman Process Equipment, BHP Billiton, Cable Sands, Ciba Specialty Chemicals, Cytec Australia Holdings, De Beers Consolidated Mines, Exxaro (Kumba Resources), Freeport-McMoRan, FL Smidth, Glencore AG, Hatch Engineering, Hydro Aluminium AS, Iluka Resources Limited (Westralian Sands), Kidd Creek Mines, Metso Minerals, Minara Resources, Mt Isa Mines, Nalco, Norilsk (Cawse), Outotec, Pechiney Aluminium, Queensland Alumina Limited, Queensland Nickel (QNI), Rio Tinto, Rusal, SNF Australia, Teck Cominco, Tiwest, True North Energy, WMC Resources Ltd, Worsley Alumina and Zinifex (Pasminco).

This research has also received support from the Australian Government's Cooperative Research Centre (CRC) program, through the AJ Parker CRC for Hydrometallurgy (the Parker Centre). Aspects of P266E were also supported by the Australian Research Council. This support is gratefully acknowledged.

The direct involvement and extensive contributions from numerous industry personnel has been crucial to the success of this work. The authors also wish to acknowledge the contributions from a wide range of CSIRO and University of Melbourne staff to this work.

\section{References}

Baek, H.K., Park, N.S., Kim, J.H., Lee, S.J. and Shin, H.S. (2005) Examination of three-dimensional flow characteristics in the distribution channel to the flocculation basin using computational fluid dynamics simulation. Journal of Water Supply: Research and Technology - AQUA 54(6), pp. 349-354.

Brouckaert, C.J. and Buckley, C.A. (1999) The use of computational fluid dynamics for improving the design and operation of water and wastewater treatment plants. Water Science and Technology 40(4-5), pp. 81-89.

Bürger, R., Bustos, M.C. and Concha, F. (1999) Settling velocities of particulate systems: 9. Phenomenological theory of sedimentation processes: numerical simulation of the transient behaviour of flocculated suspensions in an ideal batch or continuous thickener. International Journal of Mineral Processing 55, pp. 267-282.

Dixon, T., Mann, A., Hobson, P., Plaza, F., Pennesi, F. and Steindl, R. (2003) Application of CFD in the sugar industry. Third International Conference on CFD in the Minerals and Process Industries, Melbourne, Australia, December 2003, pp. 77-86.

Farrow, J.B. and Swift, J.D. (1991) Improving thickener technology. Proceedings of the Fifth AusIMM Conf on Extractive Metallurgy, Perth, Oct 1991, AusIMM, Parkville, pp. 227-232.

Farrow, J.B. and Swift, J.D. (1996a) A new procedure for assessing the performance of flocculants. International Journal of Mineral Processing 46, pp. 263-275.

Farrow, J.B. and Swift, J.D. (1996b) Agitation and residence time effects during the flocculation of mineral suspensions. Proceedings 4th International Alumina Quality Workshop, Vol. 2, Darwin, NT, June 1996. pp. 355-363.

Farrow, J.B., Johnston, R.R.M., Simic, K. and Swift, J.D. (2000) Consolidation and aggregate densification during gravity thickening. Chem. Eng. J., 80, pp. 141-148.

Flamant, O., Cockx, A., Guimet, V. and Doquang, Z. (2004) Experimental analysis and simulation of settling process. Process Safety and Environmental Protection 82, pp. 312-318.

Gladman, B., de Kretser, R.G., Rudman. M. and Scales, P.J. (2005) Effect of shear on particulate suspension dewatering. Chem. Eng. Res. Des., 83 (A7), pp. 933-936 
Goula, A.M., Kostoglou, M., Karapantsios, T.D. and Zouboulis, A.I. (2008) A CFD methodology for the design of sedimentation tanks in potable water treatment. Case study: The influence of a feed flow control baffle. Chemical Engineering Journal 140, pp. 110-121.

Heath, A. (2002) The simulation of polymer aggregation/breakage at high solid fraction in turbulent flow by population balance. Ph.D. thesis, Murdoch University, Perth, Australia.

Heath, A.R., Bahri, P.A., Fawell, P.D. and Farrow, J.B. (2006a) Polymer flocculation of calcite: Experimental results from turbulent pipe flow. AIChE Journal 52, pp. 1284-1293.

Heath, A.R., Bahri, P.A., Fawell, P.D. and Farrow, J.B. (2006b) Polymer flocculation of calcite: Population balance model. AIChE Journal 52, pp. 1641-1653.

Kahane, R.B., Schwarz, M.P. and Johnston, R.R.M. (2002) Residue thickener modelling at Worsley Alumina. Applied Mathematical Modelling 26, pp. 281-296.

Kleine D. and Reddy, B.D. (2006) Finite element simulation of unsteady flows in secondary settling tanks. Fifth International Conference on CFD in the Process Industries, Melbourne, Australia, December 2006.

Laine, S., Phan, L., Pellarin, P. and Robert, P. (1999) Operating diagnostics on a flocculator-settling tank using Fluent CFD software. Water Science and Technology 39(4), pp. 155-162.

Martin, A.D. (2004) Optimisation of clarifier-thickeners processing stable suspensions for turn-up/turn-down. Water Research 38. pp. 1568-1578.

Nguyen, T., Heath, A. and Witt, P. (2006) Population balance - CFD modelling of fluid flow, solids distribution and flocculation in thickener feedwells. Fifth International Conference on CFD in the Process Industries, Melbourne, Australia, December 2006.

Owen, A.T., Fawell, P.D. and Swift, J.D. (2007) The preparation and ageing of acrylamide/acrylate copolymer flocculant solutions. International Journal of Mineral Processing 84, pp. 3-14.

Owen, A.T., Fawell, P.D., Swift, J.D., Labbett, D.M., Benn, F.A. and Farrow, J.B. (2008) Using turbulent pipe flow to study the factors affecting polymer-bridging flocculation of mineral systems. International Journal of Mineral Processing 87, pp. 90-99.

Peloquin, G., Bui, R.T., Kocaefe, D. and Simard, G. (2005) Modélisation mathématique de la décantation de la boue rouge. The Canadian Journal of Chemical Engineering 83, pp. 458-465.

Rudman, M., Simic, K., Paterson, D.A., Strode, P., Brent, A. and Šutalo, I.D. (2008) Raking in gravity thickeners. International Journal of Mineral Processing 86, pp. 114-130.

Scales, P.J., Gladman, B.J., Usher, S.P. and Rudman, M.J. (2006) New approaches to dewatering of suspensions in the minerals industry Proceedings of XXIII International Mineral Processing Congress, Istanbul, Turkey, 3-8 September 2006, Onal, G., Acarkan, N., Celik, M.S. Arslan, F., Atesok, G., Guney, A., Sirkeci, A.A. Yuce, A.E. and Perek, K.T. (eds), Promed Ltd, Istanbul, pp. 1637-1642.

Šutalo, I.D., Paterson, D.A. and Rudman, M. (2003) Flow visualisation and computational prediction in thickener rake models. Minerals Engineering 16, pp. 93-102.

Swift, J.D., Simic, K., Johnston, R.R.M., Fawell, P.D. and Farrow J.B. (2004) A study of the polymer flocculation reaction in a linear pipe with a focused beam reflectance measurement probe. International Journal of Mineral Processing 73, pp. 103-118.

Svarovsky, L. (2000) Gravity clarification and thickening. Solid-Liquid Separation, $4^{\text {th }}$ Edition, Svarovsky, L. (ed), Butterworth-Heinemann, Oxford, pp. 166-190.

Templeton, M.R., Hofman, R. and Andrews, R.C. (2006) Case study comparisons of computational fluid dynamics (CFD) modeling versus tracer testing for determining clearwell residence times in drinking water treatment. Journal of Environmental Engineering and Science 5, pp. 529-536.

Triglavcanin, R.A. (2008) The heart of thickener performance. Paste 2008 - Proceedings of the Eleventh International Seminar on Paste and Thickened Tailings, Fourie, A.B., Jewell, R.J., Slatter, P. and Paterson, A. (eds), Australian Centre for Geomechanics, Perth, Australia, pp. 63-81.

Usher, S.P. and Scales, P.J. (2005) Steady state thickener modelling from the compressive yield stress and hindered settling function. Chemical Engineering Journal 111, pp. 253-261.

Weiss, M., Plósz, B.G., Essemiani, K. and Meinhold, J. (2007) Suction-lift sludge removal and non-Newtonian flow behaviour in circular secondary clarifiers: Numerical modelling and measurements. Chemical Engineering Journal 132, pp. 241-255.

White, R.B., Šutalo, I.D. and Nguyen, T. (2003) Fluid flow in thickener feedwell models. Minerals Engineering, 16, pp. $145-150$.

Wood, M.G., Greenfield, P.F., Howes, T., Johns, M.R. and Keller, J. (1995) Computational fluid dynamics modelling of wastewater ponds to improve design. Water Science and Technology 31(12), pp. 111-118. 